\title{
$G-\beta-\psi$ contractive-type mappings and related fixed point theorems
}

\author{
Maryam A Alghamdi ${ }^{1 *}$ and Erdal Karapınar ${ }^{2}$
}

"Correspondence:

maaalghamdi1@kau.edu.sa

${ }^{1}$ Department of Mathematics,

Sciences Faculty for Girls, King

Abdulaziz University, P.O. Box 4087,

Jeddah, 21491, Saudi Arabia

Full list of author information is

available at the end of the article

\begin{abstract}
In this paper, we introduce the notion of generalized $G-\beta-\psi$ contractive mappings which is inspired by the concept of $\alpha-\psi$ contractive mappings. We showed the existence and uniqueness of a fixed point for such mappings in the setting of complete G-metric spaces. The main results of this paper extend, generalize and improve some well-known results on the topic in the literature. We state some examples to illustrate our results. We consider also some applications to show the validity of our results.
\end{abstract}

\section{Introduction and preliminaries}

In nonlinear functional analysis, the importance of fixed point theory has been increasing rapidly as an interesting research field. One of the most important reasons for this development is the potential of application of fixed point theory not only in various branches of applied and pure mathematics, but also in many other disciplines such as chemistry, biology, physics, economics, computer science, engineering etc. We also emphasize the crucial role of celebrated results of Banach [1], known as a Banach contraction mapping principle or a Banach fixed point theorem, in the growth of this theory. In 1922, Banach proved that every contraction in a complete metric space has a unique fixed point. After this remarkable paper, a number of authors have extended/generalized/improved the Banach contraction mapping principle in various ways in different abstract spaces (see, e.g., [2-22]). One of the interesting and recent results in this direction was given by Samet et al. [23]. They defined the notion of $\alpha-\psi$ contractive mappings and proved that including the Banach fixed point theorems, some well-known fixed point results turn into corollaries of their results. Another interesting result was given in 2004 by Mustafa and Sims [24] by introducing the notion of a $G$-metric space as a generalization of the concept of a metric space. The authors characterized the Banach fixed point theorem in the context of a Gmetric space. After this result, many authors have paid attention to this space and proved the existence and uniqueness of a fixed point in the context of a $G$-metric space (see, e.g., $[11,17-20,24-48])$. In this paper, we combine these two notions by introducing a $G-\beta-\psi$ contractive mapping which is a characterization $\alpha-\psi$ contractive mappings in the context of $G$-metric spaces. Our main results generalize, extend and improve the existence results on the topic in the literature.

Let $\Psi$ be a family of functions $\psi:[0, \infty) \rightarrow[0, \infty)$ satisfying the following conditions:

(i) $\psi$ is nondecreasing;

0 2013 Alghamdi and Karapınar; licensee Springer. This is an Open Access article distributed under the terms of the Creative Commons Attribution License (http://creativecommons.org/licenses/by/2.0), which permits unrestricted use, distribution, and reproduction in any medium, provided the original work is properly cited. 
(ii) there exist $k_{0} \in \mathbb{N}$ and $a \in(0,1)$ and a convergent series of nonnegative terms $\sum_{k=1}^{\infty} v_{k}$ such that

$$
\psi^{k+1}(t) \leq a \psi^{k}(t)+v_{k}
$$

for $k \geq k_{0}$ and any $t \in \mathbb{R}^{+}$, where $\mathbb{R}^{+}=[0, \infty)$.

These functions are known in the literature as Bianchini-Grandolfi gauge functions in some sources (see, e.g. $[21,22,49])$ and as (c)-comparison functions in some other sources (see, e.g., [50]).

Lemma 1 (See [50]) If $\psi \in \Psi$, then the following hold:

(i) $\left(\psi^{n}(t)\right)_{n \in \mathbb{N}}$ converges to 0 as $n \rightarrow \infty$ for all $t \in \mathbb{R}^{+}$;

(ii) $\psi(t)<t$ for any $t \in \mathbb{R}^{+}$;

(iii) $\psi$ is continuous at 0 ;

(iv) the series $\sum_{k=1}^{\infty} \psi^{k}(t)$ converges for any $t \in \mathbb{R}^{+}$.

Very recently, Karapınar and Samet [32] introduced the following concepts.

Definition 2 Let $(X, d)$ be a metric space and $T: X \rightarrow X$ be a given mapping. We say that $T$ is a generalized $\alpha-\psi$ contractive mapping if there exist two functions $\alpha: X \times X \rightarrow[0, \infty)$ and $\psi \in \Psi$ such that

$$
\alpha(x, y) d(T x, T y) \leq \psi(M(x, y))
$$

for all $x, y \in X$, where

$$
M(x, y)=\max \{d(x, y),(d(x, T x)+d(y, T y)) / 2,(d(x, T y)+d(y, T x)) / 2\} .
$$

Clearly, since $\psi$ is nondecreasing, every $\alpha-\psi$ contractive mapping, presented in [23], is a generalized $\alpha-\psi$ contractive mapping.

Definition 3 Let $T: X \rightarrow X$ and $\alpha: X \times X \rightarrow[0, \infty)$. We say that $T$ is $\alpha$-admissible if for all $x, y \in X$, we have

$$
\alpha(x, y) \geq 1 \quad \Longrightarrow \quad \alpha(T x, T y) \geq 1
$$

Various examples of such mappings are presented in [23]. The main results in [32] are the following fixed point theorems.

Theorem 4 Let $(X, d)$ be a complete metric space and $T: X \rightarrow X$ be a generalized $\alpha-\psi$ contractive mapping. Suppose that

(i) $T$ is $\alpha$-admissible;

(ii) there exists $x_{0} \in X$ such that $\alpha\left(x_{0}, T x_{0}\right) \geq 1$;

(iii) $T$ is continuous.

Then there exists $u \in X$ such that $T u=u$.

Theorem 5 Let $(X, d)$ be a complete metric space and $T: X \rightarrow X$ be a generalized $\alpha-\psi$ contractive mapping. Suppose that 
(i) $T$ is $\alpha$-admissible;

(ii) there exists $x_{0} \in X$ such that $\alpha\left(x_{0}, T x_{0}\right) \geq 1$;

(iii) if $\left\{x_{n}\right\}$ is a sequence in $X$ such that $\alpha\left(x_{n}, x_{n+1}\right) \geq 1$ for all $n$ and $x_{n} \rightarrow x \in X$ as $n \rightarrow \infty$, then $\alpha\left(x_{n}, x\right) \geq 1$ for all $n$.

Then there exists $u \in X$ such that $T u=u$.

Theorem 6 Adding to the hypotheses of Theorem 4 (resp. Theorem 5) the condition: For all $x, y \in \operatorname{Fix}(T)$, there exists $z \in X$ such that $\alpha(x, z) \geq 1$ and $\alpha(y, z) \geq 1$, we obtain the uniqueness of the fixed point of $T$.

Mustafa and Sims [24] introduced the concept of G-metric spaces as follows.

Definition 7 [24] Let $X$ be a nonempty set and $G: X \times X \times X \rightarrow \mathbb{R}^{+}$be a function satisfying the following properties:

(G1) $G(x, y, z)=0$ if $x=y=z$;

(G2) $0<G(x, x, y)$ for all $x, y \in X$ with $x \neq y$;

(G3) $G(x, x, y) \leq G(x, y, z)$ for all $x, y, z \in X$ with $y \neq z$;

(G4) $G(x, y, z)=G(x, z, y)=G(y, z, x)=\cdots$ (symmetry in all three variables);

(G5) $G(x, y, z) \leq G(x, a, a)+G(a, y, z)$ for all $x, y, z, a \in X$ (rectangle inequality).

Then the function $G$ is called a generalized metric or, more specifically, a $G$-metric on $X$, and the pair $(X, G)$ is called a $G$-metric space.

Every G-metric on $X$ defines a metric $d_{G}$ on $X$ by

$$
d_{G}(x, y)=G(x, y, y)+G(y, x, x) \quad \text { for all } x, y \in X .
$$

Example 8 Let $(X, d)$ be a metric space. The function $G: X \times X \times X \rightarrow \mathbb{R}^{+}$, defined as

$$
G(x, y, z)=\max \{d(x, y), d(y, z), d(z, x)\}
$$

or

$$
G(x, y, z)=d(x, y)+d(y, z)+d(z, x)
$$

for all $x, y, z \in X$, is a $G$-metric on $X$.

Definition 9 [24] Let $(X, G)$ be a $G$-metric space, and let $\left\{x_{n}\right\}$ be a sequence of points of $X$. We say that $\left\{x_{n}\right\}$ is $G$-convergent to $x \in X$ if

$$
\lim _{n, m \rightarrow \infty} G\left(x, x_{n}, x_{m}\right)=0
$$

that is, for any $\varepsilon>0$, there exists $N \in \mathbb{N}$ such that $G\left(x, x_{n}, x_{m}\right)<\varepsilon$ for all $n, m \geq N$. We call $x$ the limit of the sequence and write $x_{n} \rightarrow x$ or $\lim _{n \rightarrow \infty} x_{n}=x$.

Proposition 10 [24] Let $(X, G)$ be a G-metric space. The following are equivalent:

(1) $\left\{x_{n}\right\}$ is G-convergent to $x$;

(2) $G\left(x_{n}, x_{n}, x\right) \rightarrow 0$ as $n \rightarrow \infty$; 
(3) $G\left(x_{n}, x, x\right) \rightarrow 0$ as $n \rightarrow \infty$;

(4) $G\left(x_{n}, x_{m}, x\right) \rightarrow 0$ as $n, m \rightarrow \infty$.

Definition 11 [24] Let $(X, G)$ be a $G$-metric space. A sequence $\left\{x_{n}\right\}$ is called a $G$-Cauchy sequence if for any $\varepsilon>0$, there is $N \in \mathbb{N}$ such that $G\left(x_{n}, x_{m}, x_{l}\right)<\varepsilon$ for all $n, m, l \geq N$, that is, $G\left(x_{n}, x_{m}, x_{l}\right) \rightarrow 0$ as $n, m, l \rightarrow \infty$.

Proposition 12 [24] Let $(X, G)$ be a G-metric space. Then the following are equivalent:

(1) the sequence $\left\{x_{n}\right\}$ is G-Cauchy;

(2) for any $\varepsilon>0$, there exists $N \in \mathbb{N}$ such that $G\left(x_{n}, x_{m}, x_{m}\right)<\varepsilon$ for all $n, m \geq N$.

Definition 13 [24] A $G$-metric space $(X, G)$ is called $G$-complete if every $G$-Cauchy sequence is $G$-convergent in $(X, G)$.

Lemma 14 [24] Let $(X, G)$ be a G-metric space. Then, for any $x, y, z, a \in X$, it follows that

(i) if $G(x, y, z)=0$, then $x=y=z$;

(ii) $G(x, y, z) \leq G(x, x, y)+G(x, x, z)$;

(iii) $G(x, y, y) \leq 2 G(y, x, x)$;

(iv) $G(x, y, z) \leq G(x, a, z)+G(a, y, z)$;

(v) $G(x, y, z) \leq \frac{2}{3}[G(x, y, a)+G(x, a, z)+G(a, y, z)]$;

(vi) $G(x, y, z) \leq G(x, a, a)+G(y, a, a)+G(z, a, a)$.

Definition 15 (See [24]) Let $(X, G)$ be a $G$-metric space. A mapping $T: X \rightarrow X$ is said to be $G$-continuous if $\left\{T\left(x_{n}\right)\right\}$ is $G$-convergent to $T(x)$, where $\left\{x_{n}\right\}$ is any $G$-convergent sequence converging to $x$.

In [36], Mustafa characterized the well-known Banach contraction principle mapping in the context of $G$-metric spaces in the following way.

Theorem 16 (See [36]) Let $(X, G)$ be a complete G-metric space and $T: X \rightarrow X$ be a mapping satisfying the following condition for all $x, y, z \in X$ :

$$
G(T x, T y, T z) \leq k G(x, y, z)
$$

where $k \in[0,1)$. Then $T$ has a unique fixed point.

Theorem 17 (See [36]) Let $(X, G)$ be a complete G-metric space and $T: X \rightarrow X$ be a mapping satisfying the following condition for all $x, y \in X$ :

$$
G(T x, T y, T y) \leq k G(x, y, y)
$$

where $k \in[0,1)$. Then $T$ has a unique fixed point.

Remark 18 The condition (1) implies the condition (2). The converse is true only if $k \in$ $\left[0, \frac{1}{2}\right)$. For details, see [36].

From $[24,36]$, each $G$-metric $G$ on $X$ generates a topology $\tau_{G}$ on $X$ whose base is a family of open $G$-balls $\left\{B_{G}(x, \varepsilon): x \in X, \varepsilon>0\right\}$, where $B_{G}(x, \varepsilon)=\{y \in X: G(x, y, y)<\varepsilon\}$ for all $x \in X$ 
and $\varepsilon>0$. Moreover,

$$
x \in \bar{A} \quad \Leftrightarrow \quad B_{G}(x, \varepsilon) \cap A \neq \emptyset, \quad \text { for all } \varepsilon>0 .
$$

Proposition 19 Let $(X, G)$ be a $G$-metric space and $A$ be a nonempty subset of $X$. Then $A$ is $G$-closed if for any G-convergent sequence $\left\{x_{n}\right\}$ in $A$ with limit $x$, one has $x \in A$.

\section{Main results}

We introduce the concept of generalized $\alpha-\psi$ contractive mappings as follows.

Definition 20 Let $(X, G)$ be a $G$-metric space and $T: X \rightarrow X$ be a given mapping. We say that $T$ is a generalized $G-\beta-\psi$ contractive mapping of type $\mathrm{I}$ if there exist two functions $\beta: X \times X \times X \rightarrow[0, \infty)$ and $\psi \in \Psi$ such that for all $x, y, z \in X$, we have

$$
\beta(x, y, z) G(T x, T y, T z) \leq \psi(M(x, y, z)),
$$

where

$$
M(x, y, z)=\max \left\{\begin{array}{c}
G(x, y, z), G(x, T x, T x), G(y, T y, T y), G(z, T z, T z), \\
\frac{1}{3}(G(x, T y, T y)+G(y, T z, T z)+G(z, T x, T x))
\end{array}\right\} .
$$

Definition 21 Let $(X, G)$ be a $G$-metric space and $T: X \rightarrow X$ be a given mapping. We say that $T$ is a generalized $G-\beta-\psi$ contractive mapping of type II if there exist two functions $\beta: X \times X \times X \rightarrow[0, \infty)$ and $\psi \in \Psi$ such that for all $x, y \in X$, we have

$$
\beta(x, y, y) G(T x, T y, T y) \leq \psi(M(x, y, y)),
$$

where

$$
M(x, y, y)=\max \left\{\begin{array}{c}
G(x, y, y), G(x, T x, T x), G(y, T y, T y), \\
\frac{1}{3}(G(x, T y, T y)+G(y, T y, T y)+G(y, T x, T x))
\end{array}\right\} .
$$

Remark 22 Clearly, any contractive mapping, that is, a mapping satisfying (1), is a generalized G- $\beta-\psi$ contractive mapping of type I with $\beta(x, y, z)=1$ for all $x, y, z \in X$ and $\psi(t)=k t$, $k \in(0,1)$. Analogously, a mapping satisfying (2) is a generalized $G-\beta-\psi$ contractive mapping of type II with $\beta(x, y, y)=1$ for all $x, y \in X$ and $\psi(t)=k t$, where $k \in(0,1)$.

Definition 23 Let $T: X \rightarrow X$ and $\beta: X \times X \times X \rightarrow[0, \infty)$. We say that $T$ is $\beta$-admissible if for all $x, y, z \in X$, we have

$$
\beta(x, y, z) \geq 1 \quad \Longrightarrow \quad \beta(T x, T y, T z) \geq 1 .
$$

Example 24 Let $X=[0, \infty)$ and $T: X \rightarrow X$. Define $\beta(x, y, z): X \times X \times X \rightarrow[0, \infty)$ by $T x=\ln (1+x)$ and

$$
\beta(x, y, z)= \begin{cases}e & \text { if } x \geq y \geq z \\ 0 & \text { if otherwise }\end{cases}
$$

Then $T$ is $\beta$-admissible. 
Our first result is the following.

Theorem 25 Let $(X, G)$ be a complete $G$-metric space. Suppose that $T: X \rightarrow X$ is a generalized G- $\beta-\psi$ contractive mapping of type I and satisfies the following conditions:

(i) ${ }_{a} \quad T$ is $\beta$-admissible;

(ii) $)_{a}$ there exists $x_{0} \in X$ such that $\beta\left(x_{0}, T x_{0}, T x_{0}\right) \geq 1$;

(iii) $b$ T is G-continuous.

Then there exists $u \in X$ such that $T u=u$.

Proof Let $x_{0} \in X$ be such that $\beta\left(x_{0}, T x_{0}, T x_{0}\right) \geq 1$ (such a point exists from the condition $(\text { ii) })_{a}$ ). Define the sequence $\left\{x_{n}\right\}$ in $X$ by $x_{n+1}=T x_{n}$ for all $n \geq 0$. If $x_{n_{0}}=x_{n_{0}+1}$ for some $n_{0}$, then $u=x_{n_{0}}$ is a fixed point of $T$. So, we can assume that $x_{n} \neq x_{n+1}$ for all $n$. Since $T$ is $\beta$-admissible, we have

$$
\beta\left(x_{0}, x_{1}, x_{1}\right)=\beta\left(x_{0}, T x_{0}, T x_{0}\right) \geq 1 \quad \Longrightarrow \quad \beta\left(T x_{0}, T x_{1}, T x_{1}\right)=\beta\left(x_{1}, x_{2}, x_{2}\right) \geq 1 .
$$

Inductively, we have

$$
\beta\left(x_{n}, x_{n+1}, x_{n+1}\right) \geq 1, \quad \text { for all } n=0,1, \ldots
$$

From (3) and (5), it follows that for all $n \geq 1$, we have

$$
\begin{aligned}
G\left(x_{n}, x_{n+1}, x_{n+1}\right) & =G\left(T x_{n-1}, T x_{n}, T x_{n}\right) \\
& \leq \beta\left(x_{n-1}, x_{n}, x_{n}\right) G\left(T x_{n-1}, T x_{n}, T x_{n}\right) \\
& \leq \psi\left(M\left(x_{n-1}, x_{n}, x_{n}\right)\right) .
\end{aligned}
$$

On the other hand, we have

$$
\begin{aligned}
M\left(x_{n-1}, x_{n}, x_{n}\right) & =\max \left\{\begin{array}{c}
G\left(x_{n-1}, x_{n}, x_{n}\right), G\left(x_{n-1}, T x_{n-1}, T x_{n-1}\right), G\left(x_{n}, T x_{n}, T x_{n}\right), \\
\frac{1}{3}\left(G\left(x_{n-1}, T x_{n}, T x_{n}\right)+G\left(x_{n}, T x_{n}, T x_{n}\right)+G\left(x_{n}, T x_{n-1}, T x_{n-1}\right)\right)
\end{array}\right\} \\
& =\max \left\{\begin{array}{c}
G\left(x_{n-1}, x_{n}, x_{n}\right), G\left(x_{n-1}, x_{n}, x_{n}\right), G\left(x_{n}, x_{n+1}, x_{n+1}\right), \\
\frac{1}{3}\left(G\left(x_{n-1}, x_{n+1}, x_{n+1}\right)+G\left(x_{n}, x_{n+1}, x_{n+1}\right)+G\left(x_{n}, x_{n}, x_{n}\right)\right)
\end{array}\right\} \\
& \leq \max \left\{\begin{array}{c}
G\left(x_{n-1}, x_{n}, x_{n}\right), G\left(x_{n}, x_{n+1}, x_{n+1}\right), \\
\frac{1}{3}\left(G\left(x_{n-1}, x_{n}, x_{n}\right)+G\left(x_{n}, x_{n+1}, x_{n+1}\right)+G\left(x_{n}, x_{n+1}, x_{n+1}\right)\right)
\end{array}\right\} \\
& =\max \left\{\begin{array}{c}
G\left(x_{n-1}, x_{n}, x_{n}\right), G\left(x_{n}, x_{n+1}, x_{n+1}\right), \\
\frac{1}{3}\left(G\left(x_{n-1}, x_{n}, x_{n}\right)+2 G\left(x_{n}, x_{n+1}, x_{n+1}\right)\right)
\end{array}\right\} \\
& =\max \left\{G\left(x_{n-1}, x_{n}, x_{n}\right), G\left(x_{n}, x_{n+1}, x_{n+1}\right)\right\} .
\end{aligned}
$$

Thus, we have

$$
G\left(x_{n}, x_{n+1}, x_{n+1}\right) \leq \psi\left(\max \left\{G\left(x_{n-1}, x_{n}, x_{n}\right), G\left(x_{n}, x_{n+1}, x_{n+1}\right)\right\}\right) .
$$

We consider the following two cases: 
Case 1: If $\max \left\{G\left(x_{n-1}, x_{n}, x_{n}\right), G\left(x_{n}, x_{n+1}, x_{n+1}\right)\right\}=G\left(x_{n}, x_{n+1}, x_{n+1}\right)$ for some $n$, then

$$
G\left(x_{n}, x_{n+1}, x_{n+1}\right) \leq \psi\left(G\left(x_{n}, x_{n+1}, x_{n+1}\right)\right)<G\left(x_{n}, x_{n+1}, x_{n+1}\right),
$$

which is a contradiction.

Case 2: If $\max \left\{G\left(x_{n-1}, x_{n}, x_{n}\right), G\left(x_{n}, x_{n+1}, x_{n+1}\right)\right\}=G\left(x_{n-1}, x_{n}, x_{n}\right)$, then

$$
G\left(x_{n}, x_{n+1}, x_{n+1}\right) \leq \psi\left(G\left(x_{n-1}, x_{n}, x_{n}\right)\right)
$$

for all $n \geq 1$. Since $\psi$ is nondecreasing, by induction, we get

$$
G\left(x_{n}, x_{n+1}, x_{n+1}\right) \leq \psi^{n}\left(G\left(x_{0}, x_{1}, x_{1}\right)\right) \text { for all } n \geq 1 \text {. }
$$

Using (G5) and (6), we have

$$
\begin{aligned}
G\left(x_{n}, x_{m}, x_{m}\right) \leq & G\left(x_{n}, x_{n+1}, x_{n+1}\right)+G\left(x_{n+1}, x_{n+2}, x_{n+2}\right) \\
& +G\left(x_{n+2}, x_{n+3}, x_{n+3}\right)+\cdots+G\left(x_{m-1}, x_{m}, x_{m}\right) \\
= & \sum_{k=n}^{m-1} G\left(x_{k}, x_{k+1}, x_{k+1}\right) \\
\leq & \sum_{k=n}^{m-1} \psi^{k}\left(G\left(x_{0}, x_{1}, x_{1}\right)\right) .
\end{aligned}
$$

Since $\psi \in \Psi$ and $G\left(x_{0}, x_{1}, x_{1}\right)>0$, by Lemma 1 , we get that

$$
\sum_{k=0}^{\infty} \psi^{k}\left(G\left(x_{0}, x_{1}, x_{1}\right)\right)<\infty
$$

Thus, we have

$$
\lim _{n, m \rightarrow 0} G\left(x_{n}, x_{m}, x_{m}\right)=0
$$

By Proposition 12, this implies that $\left\{x_{n}\right\}$ is a G-Cauchy sequence in the G-metric space $(X, G)$. Since $(X, G)$ is complete, there exists $u \in X$ such that $\left\{x_{n}\right\}$ is $G$-convergent to $u$. Since $T$ is $G$-continuous, it follows that $\left\{T x_{n}\right\}$ is $G$-convergent to $T u$. By the uniqueness of the limit, we get $u=T u$, that is, $u$ is a fixed point of $T$.

Definition 26 (See [51]) Let $(X, G)$ be a $G$-metric space and $T: X \rightarrow X$ be a given mapping. We say that $T$ is a $G-\beta-\psi$ contractive mapping of type $I$ if there exist two functions $\beta: X \times X \times X \rightarrow[0, \infty)$ and $\psi \in \Psi$ such that for all $x, y, z \in X$, we have

$$
\beta(x, y, z) G(T x, T y, T z) \leq \psi(G(x, y, z))
$$

by following the lines of the proof of Theorem 25 .

Corollary 27 Let $(X, G)$ be a complete G-metric space. Suppose that $T: X \rightarrow X$ is a G- $\beta-\psi$ contractive mapping of type I and satisfies the following conditions:

(i) $)_{a} \quad T$ is $\beta$-admissible; 
(ii) $)_{a}$ there exists $x_{0} \in X$ such that $\beta\left(x_{0}, T x_{0}, T x_{0}\right) \geq 1$;

(iii) ${ }_{b} T$ is G-continuous.

Then there exists $u \in X$ such that $T u=u$.

Example 28 Let $X=[0, \infty)$ be endowed with the $G$-metric

$$
G(x, y, z)=|x-y|+|y-z|+|z-x| \text { for all } x, y, z \in X .
$$

Define $T: X \rightarrow X$ by $T x=3 x$ for all $x \in X$. We define $\beta: X \times X \times X \rightarrow[0, \infty)$ in the following way:

$$
\beta(x, y, z)= \begin{cases}\frac{1}{9} & \text { if }(x, y, z) \neq(0,0,0) \\ 1 & \text { otherwise }\end{cases}
$$

One can easily show that

$$
\beta(x, y, z) G(T x, T y, T z) \leq \frac{1}{9} G(x, y, z) \quad \text { for all } x, y, z \in X .
$$

Then $T$ is a $G-\beta-\psi$ contractive mapping of type I with $\psi(t)=\frac{1}{9} t$ for all $t \in[0, \infty)$. Take $x, y, z \in X$ such that $\beta(x, y, z) \geq 1$. By the definition of $T$, this implies that $x=y=z=0$. Then we have $\beta(T x, T y, T z)=\beta(0,0,0)=1$, and so $T$ is $\beta$-admissible. All the conditions of Corollary 27 are satisfied. Here, 0 is the fixed point of $T$. Notice also that the Banach contraction mapping principle is not applicable. Indeed, $d(x, y)=|x-y|$ for all $x, y \in X$. Then we have $x \neq y d(T x, T y)=3|x-y|>k|x-y|$ for all $k \in[0,1)$.

It is clear that Theorem 16 is not applicable.

The following result can be easily concluded from Theorem 25 .

Corollary 29 Let $(X, G)$ be a complete $G$-metric space. Suppose that $T: X \rightarrow X$ is a generalized G- $\beta-\psi$ contractive mapping of type II and satisfies the following conditions:

(i) $)_{a} \quad T$ is $\beta$-admissible;

(ii) $a_{a}$ there exists $x_{0} \in X$ such that $\beta\left(x_{0}, T x_{0}, T x_{0}\right) \geq 1$;

(iii) $b$ T is G-continuous.

Then there exists $u \in X$ such that $T u=u$.

The next theorem does not require the continuity of $T$.

Theorem 30 Let $(X, G)$ be a complete G-metric space. Suppose that $T: X \rightarrow X$ is a generalized G- $\beta-\psi$ contractive mapping of type I such that $\psi$ is continuous and satisfies the following conditions:

(i) $b \quad T$ is $\beta$-admissible;

(ii) $b$ there exists $x_{0} \in X$ such that $\beta\left(x_{0}, T x_{0}, T x_{0}\right) \geq 1$;

(iii) $b$ if $\left\{x_{n}\right\}$ is a sequence in $X$ such that $\beta\left(x_{n}, x_{n+1}, x_{n+1}\right) \geq 1$ for all $n$ and $\left\{x_{n}\right\}$ is a G-convergent to $x \in X$, then $\beta\left(x_{n}, x, x\right) \geq 1$ for all $n$.

Then there exists $u \in X$ such that $T u=u$. 
Proof Following the proof of Theorem 25, we know that the sequence $\left\{x_{n}\right\}$ defined by $x_{n+1}=T x_{n}$ for all $n \geq 0$, is a $G$-Cauchy sequence in the complete $G$-metric space $(X, G)$, that is, $G$-convergent to $u \in X$. From (5) and (iii) $)_{b}$, we have

$$
\beta\left(x_{n}, u, u\right) \geq 1 \quad \text { for all } n \geq 0 \text {. }
$$

Using (8), we have

$$
\begin{aligned}
G\left(x_{n+1}, T u, T u\right) & =G\left(T x_{n}, T u, T u\right) \\
& \leq \beta\left(x_{n}, u, u\right) G\left(T x_{n}, T u, T u\right) \\
& \leq \psi\left(M\left(x_{n}, u, u\right)\right),
\end{aligned}
$$

where

$$
\begin{aligned}
M\left(x_{n}, u, u\right) & =\max \left\{\begin{array}{c}
G\left(x_{n}, u, u\right), G\left(x_{n}, T x_{n}, T x_{n}\right), G(u, T u, T u), \\
\frac{1}{3}\left(G\left(x_{n}, T u, T u\right)+G(u, T u, T u)+G\left(u, T x_{n}, T x_{n}\right)\right)
\end{array}\right\} \\
& =\max \left\{\begin{array}{c}
G\left(x_{n}, u, u\right), G\left(x_{n}, x_{n+1}, x_{n+1}\right), G(u, T u, T u), \\
\frac{1}{3}\left(G\left(x_{n}, T u, T u\right)+G(u, T u, T u)+G\left(u, x_{n+1}, x_{n+1}\right)\right)
\end{array}\right\} .
\end{aligned}
$$

Letting $n \rightarrow \infty$ in the following inequality:

$$
G\left(x_{n+1}, T u, T u\right) \leq \psi\left(M\left(x_{n}, u, u\right)\right)
$$

it follows that

$$
G(u, T u, T u) \leq \psi(G(u, T u, T u))
$$

which is a contradiction. Thus, we obtain $G(u, T u, T u)=0$, that is, by Lemma $14, u=T u$.

The following corollary can be easily derived from Theorem 30 .

Corollary 31 Let $(X, G)$ be a complete G-metric space. Suppose that $T: X \rightarrow X$ is a generalized G- $\beta-\psi$ contractive mapping of type II such that $\psi$ is continuous and satisfies the following conditions:

(i) $b \quad T$ is $\beta$-admissible;

(ii) $)_{b}$ there exists $x_{0} \in X$ such that $\beta\left(x_{0}, T x_{0}, T x_{0}\right) \geq 1$;

(iii) $)_{b}$ if $\left\{x_{n}\right\}$ is a sequence in $X$ such that $\beta\left(x_{n}, x_{n+1}, x_{n+1}\right) \geq 1$ for all $n$ and $\left\{x_{n}\right\}$ is a G-convergent to $x \in X$, then $\beta\left(x_{n}, x, x\right) \geq 1$ for all $n$.

Then there exists $u \in X$ such that $T u=u$.

With the following example, we will show that the hypotheses in Theorems 25 and 30 do not guarantee uniqueness. 
Example 32 Let $X=\{(1,0),(0,1)\} \subset \mathbb{R}^{2}$ be endowed with the following $G$-metric:

$$
G((x, y),(u, v),(z, w))=|x-u|+|u-z|+|z-x|+|y-v|+|v-w|+|w-y|
$$

for all $(x, y),(u, v),(z, w) \in X$. Obviously, $(X, G)$ is a complete metric space. The mapping $T(x, y)=(x, y)$ is trivially continuous and satisfies, for any $\psi \in \Psi$,

$$
\beta((x, y),(u, v),(z, w)) G(T(x, y), T(u, v), T(z, w)) \leq \psi(M((x, y),(u, v),(z, w)))
$$

for all $(x, y),(u, v),(z, w) \in X$, where

$$
\beta((x, y),(u, v),(z, w))= \begin{cases}1 & \text { if }(x, y)=(u, v)=(z, w), \\ 0 & \text { otherwise. }\end{cases}
$$

Thus $T$ is a generalized $G-\beta-\psi$ contractive mapping. On the other hand, for all $(x, y)$, $(u, v),(z, w) \in X$, we have

$$
\beta((x, y),(u, v),(z, w)) \geq 1 \rightarrow(x, y)=(u, v)=(z, w),
$$

which yields that

$$
T(x, y)=T(u, v)=T(z, w) \rightarrow \beta(T(x, y), T(u, v), T(z, w)) \geq 1 .
$$

Hence $T$ is $\beta$-admissible. Moreover, for all $(x, y) \in X$, we have $\beta((x, y), T(x, y), T(x, y)) \geq 1$. So, the assumptions of Theorem 25 are satisfied. Note that the assumptions of Theorem 30 are also satisfied, indeed, if $\left\{\left(x_{n}, y_{n}\right)\right\}$ is a sequence in $X$ that converges to some point $(x, y) \in$ $X$ with $\beta\left(\left(x_{n}, y_{n}\right),\left(x_{n+1}, y_{n+1}\right),\left(x_{n+1}, y_{n+1}\right)\right) \geq 1$ for all $n$, then from the definition of $\beta$, we have $\left(x_{n}, y_{n}\right)=(x, y)$ for all $n$, which implies that $\beta\left(\left(x_{n}, y_{n}\right),(x, y),(x, y)\right)=1$ for all $n$. However, in this case, $T$ has two fixed points in $X$.

Let $X$ be a set and $T$ be a self-mapping on $X$. The set of all fixed points of $T$ will be denoted by $\operatorname{Fix}(T)$.

Theorem 33 Adding the following condition to the hypotheses of Theorem 25 (resp. Theorem 30, Corollary 29, Corollary 31), we obtain the uniqueness of the fixed point of $T$.

(iv) For $x \in \operatorname{Fix}(T), \beta(x, z, z) \geq 1$ for all $z \in X$.

Proof Let $u, v \in \operatorname{Fix}(T)$ be two fixed points of $T$. By (iv), we derive

$$
\beta(u, v, v) \geq 1 .
$$

Notice that $\beta(T u, T v, T v)=\beta(u, v, v)$ since $u$ and $v$ are fixed points of $T$. Consequently, we have

$$
\begin{aligned}
G(u, v, v) & =G(T u, T v, T v) \\
& \leq \beta(u, v, v) G(T u, T v, T v) \leq \psi(M(u, v, v)),
\end{aligned}
$$


where

$$
\begin{aligned}
M(u, v, v) & =\max \left\{\begin{array}{c}
G(u, v, v), G(u, T u, T u), G(v, T v, T v), \\
\frac{1}{3}(G(u, T v, T v)+G(v, T v, T v)+G(v, T u, T u))
\end{array}\right\} \\
& =\max \left\{G(u, v, v), \frac{1}{3}(G(u, v, v)+G(v, u, u))\right\} \\
& \leq \max \left\{G(u, v, v), \frac{1}{3}(G(u, v, v)+2 G(u, v, v))\right\} \\
& =G(u, v, v) .
\end{aligned}
$$

Thus, we get that

$$
G(u, v, v) \leq \psi(M(u, v, v)) \leq \psi(G(u, v, v))<G(u, v, v)
$$

which is a contradiction. Therefore, $u=v$, i.e., the fixed point of $T$ is unique.

Corollary 34 Let $(X, G)$ be a complete $G$-metric space and let $T: X \rightarrow X$ be a given mapping. Suppose that there exists a continuous function $\psi \in \Psi$ such that

$$
G(T x, T y, T z) \leq \psi(M(x, y, z))
$$

for all $x, y, z \in X$. Then $T$ has a unique fixed point.

Corollary 35 Let $(X, G)$ be a complete G-metric space and let $T: X \rightarrow X$ be a given mapping. Suppose that there exists a function $\psi \in \Psi$ such that

$$
G(T x, T y, T z) \leq \psi(G(x, y, z))
$$

for all $x, y, z \in X$. Then $T$ has a unique fixed point.

Corollary 36 Let $(X, G)$ be a complete G-metric space and let $T: X \rightarrow X$ be a given mapping. Suppose that there exists $\lambda \in[0,1)$ such that

$$
G(T x, T y, T z) \leq \lambda \max \left\{\begin{array}{c}
G(x, y, z), G(x, T x, T x), G(y, T y, T y), G(z, T z, T z), \\
\frac{1}{3}(G(x, T y, T y)+G(y, T z, T z)+G(z, T x, T x))
\end{array}\right\}
$$

for all $x, y, z \in X$. Then $T$ has a unique fixed point.

Corollary 37 Let $(X, G)$ be a complete $G$-metric space and let $T: X \rightarrow X$ be a given mapping. Suppose that there exist nonnegative real numbers $a, b, c, d$ and e with $a+b+c+d+e<$ 1 such that

$$
\begin{aligned}
G(T x, T y, T z) \leq & a G(x, y, z)+b G(x, T x, T x)+c G(y, T y, T y)+d G(z, T z, T z) \\
& +\frac{e}{3}(G(x, T y, T y)+G(y, T z, T z)+G(z, T x, T x))
\end{aligned}
$$

for all $x, y, z \in X$. Then $T$ has a unique fixed point. 
Corollary 38 (See [40]) Let $(X, G)$ be a complete G-metric space and let $T: X \rightarrow X$ be a given mapping. Suppose that there exists $\lambda \in[0,1)$ such that

$$
G(T x, T y, T z) \leq \lambda G(x, y, z)
$$

for all $x, y, z \in X$. Then $T$ has a unique fixed point.

\section{Consequences}

\subsection{Fixed point theorems on metric spaces endowed with a partial order}

Definition 39 Let $(X, \preceq)$ be a partially ordered set and $T: X \rightarrow X$ be a given mapping. We say that $T$ is nondecreasing with respect to $\preceq$ if

$$
x, y \in X, \quad x \preceq y \quad \Longrightarrow \quad T x \preceq T y .
$$

Definition 40 Let $(X, \preceq)$ be a partially ordered set. A sequence $\left\{x_{n}\right\} \subset X$ is said to be nondecreasing with respect to $\preceq$ if

$$
x_{n} \preceq x_{n+1} \text { for all } n \text {. }
$$

Definition 41 Let $(X, \preceq)$ be a partially ordered set and $G$ be a $G$-metric on $X$. We say that $(X, \preceq, G)$ is $G$-regular if for every nondecreasing sequence $\left\{x_{n}\right\} \subset X$ such that $x_{n} \rightarrow x \in X$ as $n \rightarrow \infty, x_{n} \preceq x$ for all $n$.

Theorem 42 Let $(X, \preceq)$ be a partially ordered set and $G$ be a G-metric on $X$ such that $(X, G)$ is a complete $G$-metric space. Let $T: X \rightarrow X$ be a nondecreasing mapping with respect to $\preceq$. Suppose that there exists a function $\psi \in \Psi$ such that

$$
G(T x, T y, T y) \leq \psi(M(x, y, y))
$$

for all $x, y \in X$ with $x \preceq y$. Suppose also that the following conditions hold:

(i) there exists $x_{0} \in X$ such that $x_{0} \preceq T x_{0}$;

(ii) $T$ is $G$-continuous or $(X, \preceq, G)$ is G-regular and $\psi$ is continuous.

Then there exists $u \in X$ such that $T u=u$. Moreover, iffor $x \in \operatorname{Fix}(T), x \preceq z$ for all $z \in X$, one has the uniqueness of the fixed point.

Proof Define the mapping $\beta: X \times X \times X \rightarrow[0, \infty)$ by

$$
\beta(x, y, y)= \begin{cases}1 & \text { if } x \preceq y \\ 0 & \text { otherwise }\end{cases}
$$

From (9), for all $x, y \in X$, we have

$$
\beta(x, y, y) G(T x, T y, T y) \leq \psi(M(x, y, y)) .
$$

It follows that $T$ is a generalized G- $\beta-\psi$ contractive mapping of type II. From the condition (i), we have

$$
\beta\left(x_{0}, T x_{0}, T x_{0}\right) \geq 1
$$


By the definition of $\beta$ and since $T$ is a nondecreasing mapping with respect to $\preceq$, we have

$$
\beta(x, y, y) \geq 1 \quad \Longrightarrow \quad x \preceq y \quad \Longrightarrow \quad T x \preceq T y \quad \Longrightarrow \quad \beta(T x, T y, T y) \geq 1 .
$$

Thus $T$ is $\beta$-admissible. Moreover, if $T$ is $G$-continuous, by Theorem 25, $T$ has a fixed point.

Now, suppose that $(X, \preceq, G)$ is $G$-regular. Let $\left\{x_{n}\right\}$ be a sequence in $X$ such that $\beta\left(x_{n}, x_{n+1}, x_{n+1}\right) \geq 1$ for all $n$ and $x_{n}$ is G-convergent to $x \in X$. By Definition 41, $x_{n} \preceq x$ for all $n$, which gives us $\beta\left(x_{n}, x, x\right) \geq 1$ for all $k$. Thus, all the hypotheses of Theorem 30 are satisfied and there exists $u \in X$ such that $T u=u$. To prove the uniqueness, since $u \in \operatorname{Fix}(T)$, we have, $u \preceq z$ for all $z \in X$. By the definition of $\beta$, we get that $\beta(u, z, z) \geq 1$ for all $z \in X$. Therefore, the hypothesis (iv) of Theorem 33 is satisfied and we deduce the uniqueness of the fixed point.

Corollary 43 Let $(X, \preceq)$ be a partially ordered set and $G$ be a $G$-metric on $X$ such that $(X, G)$ is a complete $G$-metric space. Let $T: X \rightarrow X$ be a nondecreasing mapping with respect to $\preceq$. Suppose that there exists a function $\psi \in \Psi$ such that

$$
G(T x, T y, T y) \leq \psi(G(x, y, y))
$$

for all $x, y \in X$ with $x \preceq y$. Suppose also that the following conditions hold:

(i) there exists $x_{0} \in X$ such that $x_{0} \preceq T x_{0}$;

(ii) $T$ is $G$-continuous or $(X, \preceq, G)$ is G-regular.

Then there exists $u \in X$ such that $T u=u$. Moreover, if for $x \in \operatorname{Fix}(T), x \preceq z$ for all $z \in X$, one has the uniqueness of the fixed point.

Corollary 44 Let $(X, \preceq)$ be a partially ordered set and $G$ be a G-metric on $X$ such that $(X, G)$ is a complete $G$-metric space. Let $T: X \rightarrow X$ be a nondecreasing mapping with respect to $\preceq$. Suppose that there exists $\lambda \in[0,1)$ such that

$$
G(T x, T y, T y) \leq \lambda \max \left\{\begin{array}{c}
G(x, y, y), G(x, T x, T x), G(y, T y, T y), \\
\frac{1}{3}(G(x, T y, T y)+G(y, T y, T y)+G(y, T x, T x))
\end{array}\right\}
$$

for all $x, y \in X$ with $x \preceq y$. Suppose also that the following conditions hold:

(i) there exists $x_{0} \in X$ such that $x_{0} \preceq T x_{0}$;

(ii) $T$ is $G$-continuous or $(X, \preceq, G)$ is $G$-regular.

Then there exists $u \in X$ such that $T u=u$. Moreover, if for $x \in \operatorname{Fix}(T), x \preceq z$ for all $z \in X$, one has the uniqueness of the fixed point.

Corollary 45 Let $(X, \preceq)$ be a partially ordered set and $G$ be a G-metric on $X$ such that $(X, G)$ is a complete G-metric space. Let $T: X \rightarrow X$ be a nondecreasing mapping with respect to $\preceq$. Suppose that there exist nonnegative real numbers $a, b, c$ and $d$ with $a+b+c+d<1$ such that

$$
\begin{aligned}
G(T x, T y, T y) \leq & a G(x, y, y)+b G(x, T x, T x)+c G(y, T y, T y) \\
& +\frac{d}{3}(G(x, T y, T y)+G(y, T y, T y)+G(y, T x, T x))
\end{aligned}
$$


for all $x, y \in X$ with $x \preceq y$. Suppose also that the following conditions hold:

(i) there exists $x_{0} \in X$ such that $x_{0} \preceq T x_{0}$;

(ii) $T$ is $G$-continuous or $(X, \preceq, G)$ is $G$-regular.

Then there exists $u \in X$ such that $T u=u$. Moreover, iffor $x \in \operatorname{Fix}(T), x \preceq z$ for all $z \in X$, one has the uniqueness of the fixed point.

Corollary 46 Let $(X, \preceq)$ be a partially ordered set and $G$ be a G-metric on $X$ such that $(X, G)$ is a complete $G$-metric space. Let $T: X \rightarrow X$ be a nondecreasing mapping with respect to $\preceq$. Suppose that there exists a constant $\lambda \in[0,1)$ such that

$$
G(T x, T y, T y) \leq \lambda G(x, y, y)
$$

for all $x, y \in X$ with $x \preceq y$. Suppose also that the following conditions hold:

(i) there exists $x_{0} \in X$ such that $x_{0} \preceq T x_{0}$;

(ii) $T$ is $G$-continuous or $(X, \preceq, G)$ is $G$-regular.

Then there exists $u \in X$ such that $T u=u$. Moreover, if for $x \in \operatorname{Fix}(T), x \preceq z$ for all $z \in X$, one has the uniqueness of the fixed point.

\subsection{Cyclic contraction}

Now, we will prove our results for cyclic contractive mappings in a G-metric space.

Theorem 47 (See [30,33]) Let A, B be a nonempty G-closed subset of a complete G-metric space $(X, G)$. Suppose also that $Y=A \cup B$ and $T: Y \rightarrow Y$ is a given self-mapping satisfying

$$
T(A) \subseteq B \text { and } \quad T(B) \subseteq A .
$$

If there exists a continuous function $\psi \in \Psi$ such that

$$
G(T x, T y, T y) \leq \psi(M(x, y, y)), \quad \forall x \in A, y \in B,
$$

then $T$ has a unique fixed point $u \in A \cap B$, that is, $T u=u$.

Proof Notice that $(Y, G)$ is a complete $G$-metric space since $A, B$ is a closed subset of a complete $G$-metric space $(X, G)$. We define $\beta: X \times X \times X \rightarrow[0, \infty)$ in the following way:

$$
\beta(x, y, y)= \begin{cases}1 & \text { if }(x, y) \in(A \times B) \cup(B \times A) \\ 0 & \text { otherwise }\end{cases}
$$

Due to the definition of $\beta$ and the assumption (12), we have

$$
\beta(x, y, y) G(T x, T y, T y) \leq \psi(M(x, y, y)), \quad \forall x, y \in Y .
$$

Hence, $T$ is a generalized $G-\beta-\psi$ contractive mapping.

Let $(x, y) \in Y \times Y$ be such that $\beta(x, y, y) \geq 1$. If $(x, y) \in A \times B$ then by the assumption (11), $(T x, T y) \in B \times A$, which yields that $\beta(T x, T y, T y) \geq 1$. If $(x, y) \in B \times A$, we get again $\beta(T x, T y, T y) \geq 1$ by analogy. Thus, in any case, we have $\beta(T x, T y, T y) \geq 1$, that is, 
$T$ is $\beta$-admissible. Notice also that for any $z \in A$, we have $(z, T z) \in A \times B$, which yields $\beta(z, T z, T z) \geq 1$.

Take a sequence $\left\{x_{n}\right\}$ in $X$ such that $\beta\left(x_{n}, x_{n+1}, x_{n+1}\right) \geq 1$ for all $n$ and $x_{n} \rightarrow u \in X$ as $n \rightarrow \infty$. Regarding the definition of $\beta$, we derive that

$$
\left(x_{n}, x_{n+1}\right) \in(A \times B) \cup(B \times A) \text { for all } n \text {. }
$$

By assumption, $A, B$ and hence $(A \times B) \cup(B \times A)$ is a $G$-closed set. Hence, we get that $(u, u) \in(A \times B) \cup(B \times A)$, which implies that $u \in A \cap B$. We conclude, by the definition of $\beta$, that $\beta\left(x_{n}, u, u\right) \geq 1$ for all $n$.

Now, all hypotheses of Theorem 30 are satisfied and we conclude that $T$ has a fixed point. Next, we show the uniqueness of a fixed point $u$ of $T$. Since $u \in \operatorname{Fix}(T)$ and $u \in A \cap B$, we get $\beta(u, a, a) \geq 1$ for all $a \in Y$. Thus, the condition (iv) of Theorem 33 is satisfied.

\section{Competing interests}

The authors declare that they have no competing interests.

\section{Authors' contributions}

All authors read and approved the final manuscript.

\section{Author details}

'Department of Mathematics, Sciences Faculty for Girls, King Abdulaziz University, P.O. Box 4087, Jeddah, 21491, Saudi Arabia. ${ }^{2}$ Department of Mathematics, Atilim University, Incek, Ankara 06836, Turkey.

\section{Acknowledgements}

The research of the first author was partially supported by the Deanship of Scientific Research (DSR), King Abdulaziz University, Jeddah, Saudi Arabia.

Received: 13 December 2012 Accepted: 9 February 2013 Published: 27 February 2013

\section{References}

1. Banach, S: Sur les opérations dans les ensembles abstraits et leur application aux equations itegrales. Fundam. Math. 3, 133-181 (1922)

2. Abbas, $M$, Sintunavarat, $W$, Kumam, $P$ : Coupled fixed point of generalized contractive mappings on partially ordered G-metric spaces. Fixed Point Theory Appl. 2012, Article ID 31 (2012)

3. Agarwal, RP, Alghamdi, MA, Shahzad, N: Fixed point theory for cyclic generalized contractions in partial metric spaces. Fixed Point Theory Appl. 2012, Article ID 40 (2012)

4. Aydi, H, Vetro, C, Sintunavarat, W, Kumam, P: Coincidence and fixed points for contractions and cyclical contractions in partial metric spaces. Fixed Point Theory Appl. 2012, Article ID 124 (2012)

5. Ćirić, L, Lakshmikantham, V: Coupled fixed point theorems for nonlinear contractions in partially ordered metric spaces. Nonlinear Anal. 70, 4341-4349 (2009)

6. Gnana-Bhaskar, T, Lakshmikantham, V: Fixed point theorems in partially ordered metric spaces and applications. Nonlinear Anal. 65, 1379-1393 (2006)

7. Guo, D, Lakshmikantham, V: Coupled fixed points of nonlinear operators with applications. Nonlinear Anal., Theory Methods Appl. 11, 623-632 (1987)

8. Karapınar, E: Fixed point theory for cyclic weak $\phi$-contraction. Appl. Math. Lett. 24(6), 822-825 (2011)

9. Karapınar, E, Sadaranagni, K: Fixed point theory for cyclic $(\phi-\psi)$-contractions. Fixed Point Theory Appl. 2011, Article ID 69 (2011)

10. Karapınar, E: Coupled fixed point theorems for nonlinear contractions in cone metric spaces. Comput. Math. Appl. 59, 3656-3668 (2010)

11. Nashine, HK, Sintunavarat, W, Kumam, P: Cyclic generalized contractions and fixed point results with applications to an integral equation. Fixed Point Theory Appl. 2012, Article ID 217 (2012)

12. Kirk, WA, Srinivasan, PS, Veeramani, P: Fixed points for mappings satisfying cyclical contractive conditions. Fixed Point Theory Appl. 4(1), 79-89 (2003)

13. Pacurar, M, Rus, IA: Fixed point theory for cyclic $\varphi$-contractions. Nonlinear Anal. 72, 1181-1187 (2010)

14. Petric, MA: Some results concerning cyclical contractive mappings. Gen. Math. 18(4), 213-226 (2010)

15. Petruşel, A, Rus, IA: Fixed point theorems in ordered L-spaces. Proc. Am. Math. Soc. 134, 411-418 (2006)

16. Rus, IA: Cyclic representations and fixed points. Ann. "Tiberiu Popoviciu" Sem. Funct. Equ. Approx. Convexity 3, 171-178 (2005)

17. Sintunavarat, W, Kumam, P: Coupled coincidence and coupled common fixed point theorems in partially ordered metric spaces. Thai J. Math. 10(3), 551-563 (2012)

18. Sintunavarat, W, Cho, YJ, Kumam, P: Coupled fixed-point theorems for contraction mapping induced by cone ball-metric in partially ordered spaces. Fixed Point Theory Appl. 2012, Article ID 128 (2012) 
19. Sintunavarat, W, Kim, JK, Kumam, P: Fixed point theorems for a generalized almost $(\phi, \varphi)$-contraction with respect to S in ordered metric spaces. J. Inequal. Appl. 2012, Article ID 263 (2012)

20. Sintunavarat, W, Kumam, P: Common fixed point theorem for cyclic generalized multi-valued contraction mappings. Appl. Math. Lett. 25(11), 1849-1855 (2012)

21. Bianchini, RM, Grandolfi, M: Transformazioni di tipo contracttivo generalizzato in uno spazio metrico. Atti Accad. Naz. Lincei, Rend. Cl. Sci. Fis. Mat. Nat. 45, 212-216 (1968)

22. Proinov, PD: New general convergence theory for iterative processes and its applications to Newton Kantorovich type theorems. J. Complex. 26, 3-42 (2010)

23. Samet, B, Vetro, C, Vetro, P: Fixed point theorem for $\alpha-\psi$ contractive type mappings. Nonlinear Anal. 75, 2154-2165 (2012)

24. Mustafa, Z, Sims, B: A new approach to generalized metric spaces. J. Nonlinear Convex Anal. 7(2), $289-297$ (2006)

25. Aydi, H, Damjanović, B, Samet, B, Shatanawi, W: Coupled fixed point theorems for nonlinear contractions in partially ordered G-metric spaces. Math. Comput. Model. 54, 2443-2450 (2011)

26. Choudhury, BS, Maity, P: Coupled fixed point results in generalized metric spaces. Math. Comput. Model. 54, 73-79 (2011)

27. Aydi, H, Karapınar, E, Shatanawi, W: Tripled fixed point results in generalized metric spaces. J. Appl. Math. 2012, Article ID 314279 (2012)

28. Aydi, H, Karapınar, E, Mustafa, Z: On Common Fixed Points in G-Metric Spaces Using (E.A) Property. Comput. Math. Appl. 64(6), 1944-1956 (2012)

29. Aydi, H, Karapınar, E, Shatanawi, W: Tripled common fixed point results for generalized contractions in ordered generalized metric spaces. Fixed Point Theory Appl. 2012, Article ID 101 (2012)

30. Aydi, H: Generalized cyclic contractions in G-metric spaces. J. Nonlinear Sci. Appl. (in press)

31. Karapınar, E, Kaymakcalan, B, Tas, K: On coupled fixed point theorems on partially ordered G-metric spaces. J. Inequal. Appl. 2012, Article ID 200 (2012)

32. Karapınar, E, Samet, B: Generalized $(\alpha-\psi)$ contractive type mappings and related fixed point theorems with applications. Abstr. Appl. Anal. 2012, Article ID 793486 (2012)

33. Karapınar, E, Erhan, IM, Ulus, AY: Cyclic contractions on G-metric spaces. Abstr. Appl. Anal. 2012, Article ID 182947 (2012)

34. Ding, HS, Karapınar, E: A note on some coupled fixed point theorems on G-metric space. J. Inequal. Appl. 2012, Article ID 170 (2012)

35. Gul, U, Karapınar, E: On almost contraction in partially ordered metric spaces viz implicit relation. J. Inequal. Appl. 2012, Article ID 217 (2012)

36. Mustafa, Z: A new structure for generalized metric spaces with applications to fixed point theory. Ph.D. Thesis, The University of Newcastle, Australia (2005)

37. Mustafa, Z, Aydi, H, Karapınar, E: On common fixed points in image-metric spaces using (E.A) property. Comput. Math. Appl. (2012). doi:10.1016/j.camwa.2012.03.051

38. Mustafa, Z, Obiedat, H, Awawdeh, F: Some fixed point theorem for mapping on complete G-metric spaces. Fixed Point Theory Appl. 2008, Article ID 189870 (2008)

39. Mustafa, Z, Khandaqji, M, Shatanawi, W: Fixed point results on complete G-metric spaces. Studia Sci. Math. Hung. 48, 304-319 (2011)

40. Mustafa, Z, Sims, B: Fixed point theorems for contractive mappings in complete G-metric spaces. Fixed Point Theory Appl. 2009, Article ID 917175 (2009)

41. Mustafa, Z, Shatanawi, W, Bataineh, M: Existence of fixed point results in G-metric spaces. Int. J. Math. Math. Sci. 2009, Article ID 283028 (2009)

42. Shatanawi, W: Fixed point theory for contractive mappings satisfying $\Phi$-maps in G-metric spaces. Fixed Point Theory Appl. 2010, Article ID 181650 (2010)

43. Shatanawi, W: Some fixed point theorems in ordered G-metric spaces and applications. Abstr. Appl. Anal. 2011 Article ID 126205 (2011)

44. Shatanawi, W: Coupled fixed point theorems in generalized metric spaces. Hacet. J. Math. Stat. 40(3), $441-447$ (2011)

45. Shatanawi, W, Abbas, M, Nazir, T: Common coupled coincidence and coupled fixed point results in two generalized metric spaces. Fixed Point Theory Appl. 2011, Article ID 80 (2011)

46. Sintunavarat, W, Cho, YJ, Kumam, P: Common fixed point theorems for c-distance in ordered cone metric spaces. Comput. Math. Appl. 62, 1969-1978 (2011)

47. Tahat, N, Aydi, H, Karapınar, E, Shatanawi, W: Common fixed points for single-valued and multi-valued maps satisfying a generalized contraction in G-metric spaces. Fixed Point Theory Appl. 2012, Article ID 48 (2012)

48. Agarwal, RP, Karapınar, E: Remarks on some coupled fixed point theorems in G-metric spaces. Fixed Point Theory Appl. 2013, Article ID 2 (2013)

49. Proinov, PD: A generalization of the Banach contraction principle with high order of convergence of successive approximations. Nonlinear Anal., Theory Methods Appl. 67, 2361-2369 (2007)

50. Berinde, V: Iterative Approximation of Fixed Points. Editura Efemeride, Baia Mare (2002)

51. Alghamdi, MA, Karapınar, E: G- $\beta-\psi$ contractive type mappings and related fixed point theorems. Preprint

doi:10.1186/1029-242X-2013-70

Cite this article as: Alghamdi and Karapınar: $G-\beta-\psi$ contractive-type mappings and related fixed point theorems.

Journal of Inequalities and Applications 2013 2013:70. 